\title{
IMPACT OF RAW MATERIAL PROPERTIES AND AGGLOMERATION PRESSURE ON SELECTED PARAMETERS OF GRANULATES OBTAINED FROM WILLOW AND BLACK LOCUST BIOMASS
}

\author{
Marek Wrobel, Krzysztof Mudryk, Marcin Jewiarz, Adrian Knapczyk \\ University of Agriculture in Krakow, Poland \\ marek.wrobel@urk.edu.pl,krzysztof.mudryk@urk.edu.pl,marcin.jewiarz@urk.edu.pl, \\ adrian.knapczyk91@gmail.com
}

\begin{abstract}
Woody biomass is an very important component of contemporary energy policies in many countries. It is mainly used as a raw material for the production of compacted solid biofuels (pellets and briquettes). Biomass, due to the different origin, is characterized by high variability of parameters, which significantly affect the quality of the obtained solid biofuels. Biomass processing technologies also have a significant impact on the final product properties. Therefore, in aglomerated solid biofuel production it is very important to know the impacts of the main factors (material and process) influencing on the granutale parameters. Thanks to this knowledge, it is possible to intensify the influence of the parameters improving the product quality, as well as to eliminate those that are decreasing this quality. Mainly the quality parameters of compacted solid biofuels are connected with a density (bulk, envelope and absolute density, porosity ect.). These parameters are very important from the viewpoint of logistics processes, burning processes, etc. The results of the research were presented, the aim of which was to determine the effect of raw material fragmentation degree (willow and black locust biomass) and agglomeration pressure on the parameters of granulates. The research material was obtained by grinding the willow and black locust biomass on a mill with sieves of hole diameter 8, 6 and $4 \mathrm{~mm}$. Raw material particle size distribution, porosity, envelope and bulk density have been specified. Granulates were made of material with a moisture content of $12 \%$ on the pressing stand by compacting pressure 100,150 and $200 \mathrm{MPa}$. Envelope density, compaction degree and index were determined for the granules.
\end{abstract}

Keywords: agglomeration, density, biomass, willow, black locust.

\section{Introduction}

The energy policy of European countries assumes replacing systems based on fossil fuels with systems that use renewable energy such as solar-hydrogen fuel cell energy systems or hybrid heating systems [1-3]. Especially biomass is a very important part of contemporary energy policies in many countries. Wood has always been used as fuel, but currently, various types of biomass (woody, herbaceous, fruit, aquatic or their blends and mixtures [4]) are used as a raw material for the production of compacted solid biofuels (pellets and briquettes). Research is also being carried out to determine the possibilities of adding other raw materials to biomass and production of solid biofuels, for example: cassava stem powder [5] or municipal sewage sludge [6; 7], as well as research on the possibility of processing biomass for the production of compacted fuels, especially on drying processing [8-10].

The quality parameters of compact biofuels are comparable to wood parameters and in many cases they exceed them $[11 ; 12]$. Biomass as raw material, due to the different origin, is characterized by high variability of parameters, which significantly affect the quality of the obtained solid biofuels. The physical properties of these materials such as: size distribution, density, porosity, moisture content, are varied [13-16]. The mechanical properties of solid biofuels depend of the raw material particle size and shape. Generally small particles with a large surface area and many points of contact between them are desirable. For the biomass densification process it will increase the density and durability of pellets or briquettes [17-20].

Known and commonly used biomass processing technologies also have a significant impact on the final product properties: increase of the temperature and pressure increases the quality of the granulate [21, 22]. Therefore, in aglomerated solid biofuel production it is very important to know the impacts of the main factors (material and process) influencing on the granutale parameters. Thanks to this knowledge, it is possible to intensify the influence of the parameters improving the product quality, as well as to eliminate those that are decreasing this quality. Mainly quality parameters of compacted solid biofuels are connected with a density (bulk, envelope and absolute density, porosity ect.) and durability. These parameters are very important from the viewpoint of logistics processes, burning processes, etc. 
In the paper, results of the research are presented, the aim of which was to determine the effect of the raw material fragmentation degree (willow and black locust biomass) and agglomeration pressure on the parameters of granulates. The raw material fragmentation is directly related with energy for the process. The smaller degree of fragmentation means lower energy consumption. Therefore, it is important to know what degree of fragmentation allows to obtain granules with the required density.

\section{Materials and methods}

Two types of woody raw materials were used in the research - basket willow biomass (soft wood) and black locust biomass (hardwood). Six-year stems of black locust and three-year stems of willow have been used.

Willow or rather basket willow Salix viminalis L. is native species in Europe and Asia. It is growing up to 3-6 m tall as a multistemmed shrub. It has characteristic long, straight stems covered with gray-green bark. Rapid growth and high yield as well as good energy parameters of willow biomass cause that it is considered as an classic energy plant intended for short rotation coppice.

Black locust Robinia pseudoacacia L. native to the southeastern United States, commonly known as false acacia is a medium-sized deciduous tree. It is widely planted species in Europe, Southern Africa and Asia, it is considered as invasive species in Poland. However, due to very good energy parameters and rapid growth, it is considered as a valuable energy species recommended for energy crops.

The research material, after chipping, was ground on a hammer mill King (POR Micucci System Srl) using a sieve with a diameter of 8,6 and $4 \mathrm{~mm}$. Shaker LPzE-4e Morek Multiserw equipped with a set of sieves was used for determination of the material particle size distribution. Sieves with round hole diameter of 16,8 and $3.15 \mathrm{~mm}$ and braided screen with square holes of $2.8 ; 2 ; 1.4 ; 1 ; 0.5$ and 0.25 $\mathrm{mm}$ were used (according to the standards [23,24]). Biomass particle density and granulate density (envelope density), was determined using GeoPyc 1360 (Micromeritics Instrument Corp.). Detailed description of the method can be found in [25]. Bulk density of raw material was determined according to the standard [26] using a container with the volume of $5 \mathrm{dm}^{3}$. Based on the results of the material particle density and bulk density measurements, the porosity was determined. Moisture content determination in the material was carried out according to the standard [27].

Granulates with a diameter of $18 \mathrm{~mm}$ were made from material with a moisture content of $12 \%$ on the pressing stand by compacting pressure 100, 150 and $200 \mathrm{MPa}$. For the obtained granulates the compaction degree and compaction index were calculated. The research series consisted of 10 granules made for each test condition. Results were presented as the average result for the whole series. Compaction degree is a relation of the granule envelope density to the raw material bulk density and indicates, how much the granule envelope density increases in relation to the material bulk density. Compaction index is a relation of the granule envelope density to the raw material envelope density and shows, how the granule density approaches or exceeds the raw material envelope density.

\section{Results and discussion}

Raw material moisture was at the level $12 \%$. Raw material particle size distribution is presented in Figure 1 - black locust and Figure 2 - willow, both in 3 degrees of fragmentation. On the diagrams the average percentage share of fractions in the milled samples of biomass was presented. Black locust samples have the highest share of the fraction: above 1.4-2 $\mathrm{mm}(31.8 \%)$ for material $4 \mathrm{~mm}$ degree of fragmentation, above 1.4-2 $\mathrm{mm}$ and above 2-3.15 mm (28.1 and $27.5 \%$ ) for material $6 \mathrm{~mm}$, and above 2-3.15 mm (31.9\%) for material $8 \mathrm{~mm}$.

In case of the willow samples, the biggest fraction in material $4 \mathrm{~mm}$ degree of fragmentation is the fraction above 1.4-2 $\mathrm{mm}(36.7 \%)$, in material $6 \mathrm{~mm}$ the fraction above 1.4-2 $\mathrm{mm}(32.5 \%)$ and in material $8 \mathrm{~mm}$ also the fraction above $1.4-2 \mathrm{~mm}(32.6 \%)$. These fractions have a higher share compared to black locust samples. The fractions below $1 \mathrm{~mm}$ have a higher share in black locust samples.

The comparison of cumulative distribution of the particle size allows to indicate exactly the difference between the fragmentation of the milled materials (Fig. 3 and Fig. 4). These graphs show clear differences between the degrees of fragmentation of the tested materials. Calculated central value 
of the particle size $d_{50}$ [24], for each material and for each degree of fragmentation indicates the difference between them (see Table 1). So, using the same milling conditions, the obtained materials differ in terms of the degree of fragmentation. Based on the median size of the particle $d_{50}$ value, it can be stated that the willow samples are less fragmented in relation to the black locust samples, what may affect the agglomeration process.

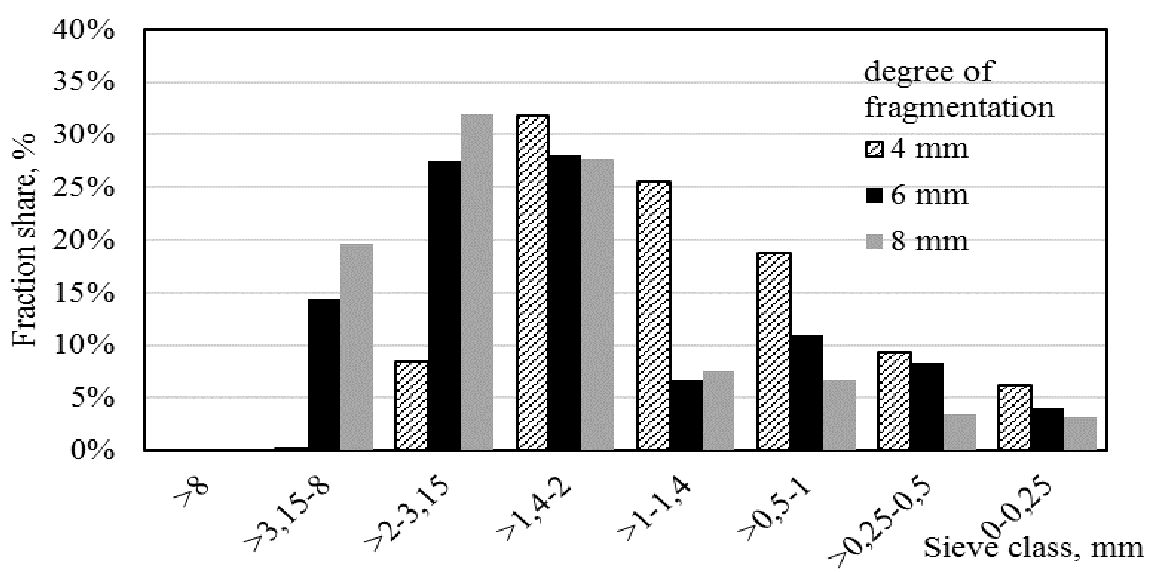

Fig. 1. Black locust particle size distribution

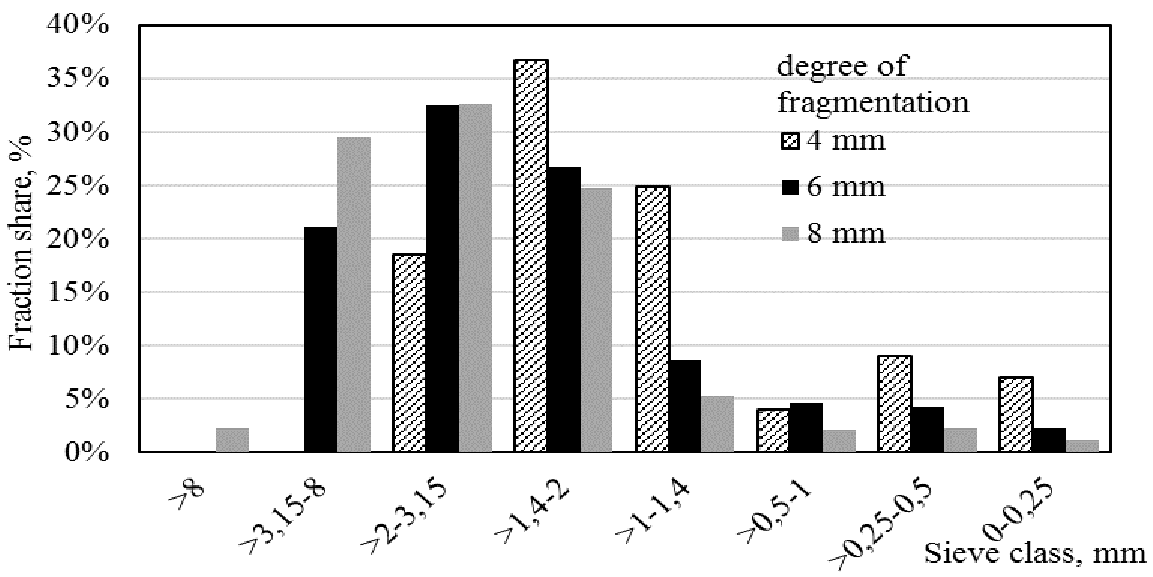

Fig. 2. Willow particle size distribution

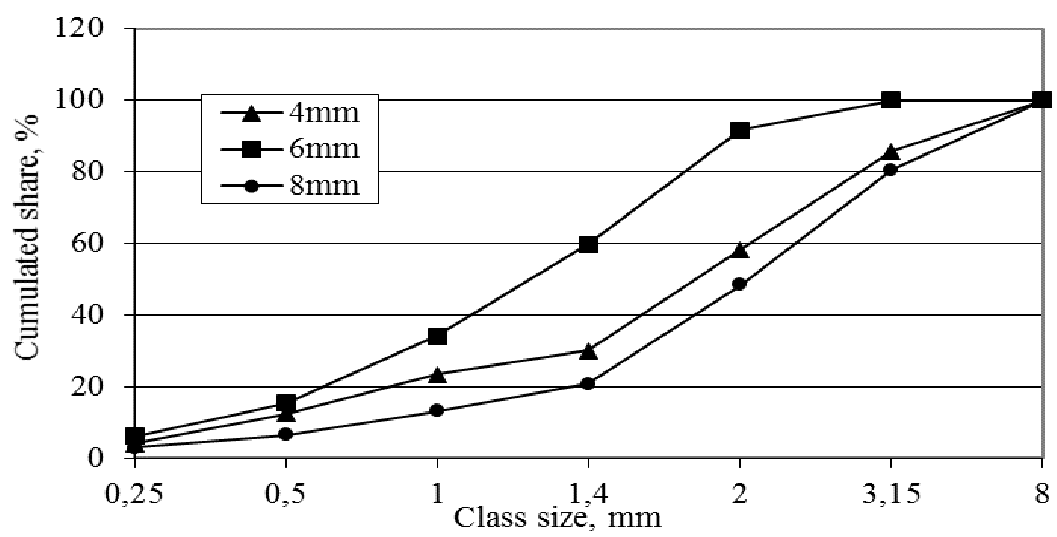

Fig. 3. Black locust cumulative distribution of particle size

Values of the parameters of the investigated materials are presented in Table 1. Envelope densities and bulk densities of both species differ. For both materials, the bulk density grows as the degree of fragmentation increases. However, despite the different bulk density, the porosity values of both materials are similar, so the degree of filling the space with material is similar for both biomass kinds. 


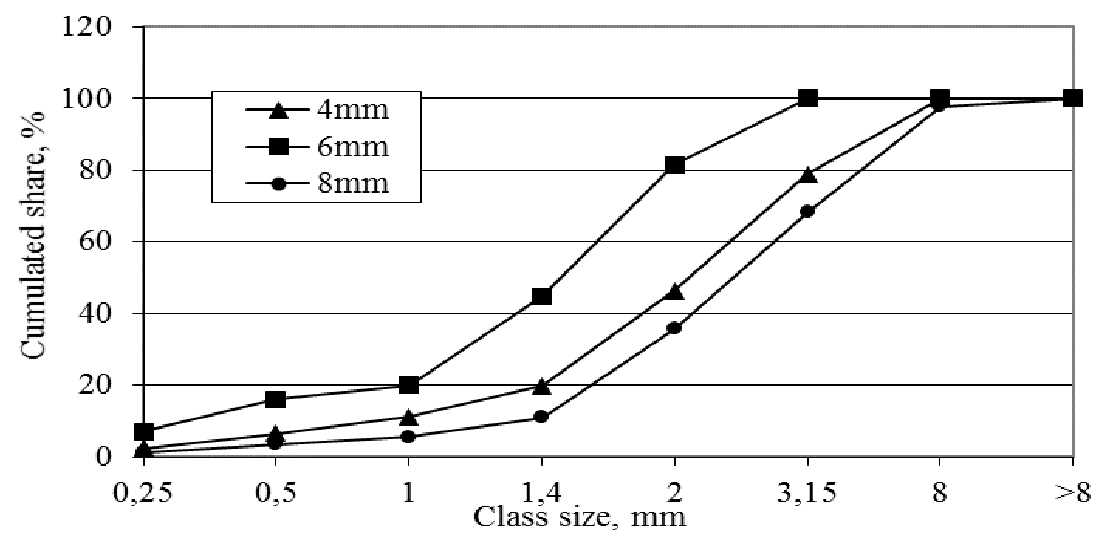

Fig. 4. Willow cumulative distribution of particle size

Table 1

Investigated raw materials - values of the parameters

\begin{tabular}{|c|c|c|c|c|c|c|}
\hline Material & \multicolumn{3}{|c|}{ Black locust } & \multicolumn{3}{c|}{ Willow } \\
\hline Degree of fragmentation, $\mathbf{~ m m}$ & 4 & 6 & 8 & 4 & 6 & 8 \\
\hline Median size of the particle $\boldsymbol{d}_{\mathbf{5 0}}, \mathbf{~ m m}$ & 1.25 & 1.82 & 2.05 & 1.48 & 2.13 & 2.51 \\
\hline Envelope density, $\mathbf{g} \cdot \mathbf{c m}^{-\mathbf{3}}$ & \multicolumn{3}{|c|}{0.69} & \multicolumn{3}{|c|}{0.52} \\
\hline Bulk density, $\mathbf{g} \mathbf{c m}^{-\mathbf{3}}$ & 0.28 & 0.26 & 0.25 & 0.22 & 0.2 & 0.19 \\
\hline Porosity, \% & 59.6 & 62.5 & 63.9 & 57.8 & 61.6 & 63.5 \\
\hline
\end{tabular}

The values of the granulate parameters (envelope density, compaction index and compaction degree) are presented in Table 2.

Parameter value of granulates obtained from investigated biomass samples

\begin{tabular}{|c|c|c|c|c|c|}
\hline Material & $\begin{array}{c}\text { Fragmentation } \\
\text { degree, } \mathbf{m m}\end{array}$ & $\begin{array}{l}\text { Agglomeration } \\
\text { pressure, MPa }\end{array}$ & $\begin{array}{c}\text { Envelope } \\
\text { density, } \mathrm{g} \cdot \mathbf{c m}^{-3}\end{array}$ & $\begin{array}{c}\text { Compaction } \\
\text { degree }\end{array}$ & $\begin{array}{c}\text { Compaction } \\
\text { index }\end{array}$ \\
\hline \multirow{9}{*}{ Black locust } & \multirow{3}{*}{ 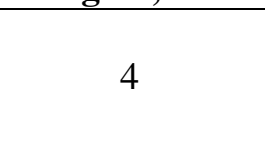 } & 100 & 0.71 & 2.54 & 1.02 \\
\hline & & 150 & 0.73 & 2.61 & 1.05 \\
\hline & & 200 & 0.74 & 2.64 & 1.07 \\
\hline & \multirow{3}{*}{6} & 100 & 0.66 & 2.54 & 0.95 \\
\hline & & 150 & 0.68 & 2.62 & 0.98 \\
\hline & & 200 & 0.7 & 2.69 & 1.01 \\
\hline & \multirow{3}{*}{8} & 100 & 0.65 & 2.60 & 0.94 \\
\hline & & 150 & 0.66 & 2.64 & 0.95 \\
\hline & & 200 & 0.69 & 2.76 & 1.00 \\
\hline \multirow{9}{*}{ Willow } & \multirow{3}{*}{4} & 100 & 0.74 & 3.36 & 1.42 \\
\hline & & 150 & 0.79 & 3.59 & 1.52 \\
\hline & & 200 & 0.82 & 3.73 & 1.57 \\
\hline & \multirow{3}{*}{6} & 100 & 0.72 & 3.60 & 1.38 \\
\hline & & 150 & 0.76 & 3.80 & 1.46 \\
\hline & & 200 & 0.8 & 4.00 & 1.54 \\
\hline & \multirow{3}{*}{8} & 100 & 0.72 & 3.79 & 1.38 \\
\hline & & 150 & 0.74 & 3.89 & 1.42 \\
\hline & & 200 & 0.79 & 4.16 & 1.52 \\
\hline
\end{tabular}

Despite the higher value of the envelope density and bulk density for black locust, the granule envelope density is lower compared to the granules from willow. In both cases, the envelope density of the granules increases with the increase of the agglomeration pressure and degree of fragmentation. The compaction degree for black locust was in the range 2.54-2.76, while for willow in the range 3.36- 
4.16. Whereas, the compaction index of black locust was in the range 0.94-1.07 and for willow it is higher and it is in the range 1.38-1.57.

\section{Conclusions}

1. The investigated materials differ in terms of the degree of fragmentation despite the same milling conditions, it can be stated that the willow samples are less fragmented in relation to the black locust samples.

2. For both materials, the bulk density grows as the degree of fragmentation increases. Black locust bulk density and envelope density is higher compared to willow, but the porosity values of both materials are similar. It means that the degree of filling the space is similar for both materials.

3. Black locust granule envelope density is lower (range 0.65-0.74) compared to the granules from willow (range 0.72-0.820. In both cases, the envelope density of the granules increases with the increase of the agglomeration pressure and the degree of fragmentation.

4. The compaction degree and the compaction index value for black locust are lower than for willow.

5. On the basis of the obtained results it can be stated that willow biomass has better agglomeration properties then black locust biomass.

\section{Acknowledgements} Poland.

This research was financed by the Ministry of Science and Higher Education of the Republic of

\section{References}

[1] Klessmann C., Held A., Rathmann M., Ragwitz, M. Status and perspectives of renewable energy policy and deployment in the European Union - What is needed to reach the 2020 targets? Energy policy, 39(12), 2011. pp. 7637-7657.

[2] Yilanci A., Dincer I., Ozturk, H.K. A review on solar-hydrogen/fuel cell hybrid energy systems for stationary applications. Progress in Energy and Combustion Science, 35(3), 2009. pp. 231-244.

[3] Kurpaska. S., Pedryc. N. Analysis of the efficiency of a hybrid foil tunnel heating system. E3S Web of Conferences. vol. 19. 2017. pp.1-4. doi.org/10.1051/e3sconf/20171901012

[4] ISO 17225-1:2014 Solid biofuels - Fuel specifications and classes - Part 1: General requirements

[5] Larsson S., Lockneus O., Xiong S., Samuelsson R. Cassava stem powder as an additive in biomass fuel pellet production. Energy \& Fuels, 29(9), 2015. pp. 5902-5908.

[6] Brzychczyk B., Hebda T., Giełżecki J. Energy Characteristics of Compacted Biofuel with Stabilized Fraction of Municipal Waste. In: Mudryk K., Werle S. (eds) Renewable Energy Sources: Engineering, Technology, Innovation. Springer Proceedings in Energy. Springer, Cham. Springer. 2018. pp. 451-462. doi.org/10.1007/978-3-319-72371-6_44

[7] Brzychczyk B., Hebda T., Giełżecki J. Physical and Chemical Properties of Pellets Produced from the Stabilized Fraction of Municipal Sewage Sludge. In: Mudryk K., Werle S. (eds) Renewable Energy Sources: Engineering, Technology, Innovation. Springer Proceedings in Energy. Springer, Cham. Springer. 2018. pp. 613-622. doi.org/10.1007/978-3-319-72371-6_60

[8] Francik S., Łapczyńska-Kordon B., Francik R., Wójcik A. Modeling and simulation of biomass drying using Artificial Neural Networks. In: Mudryk K., Werle S. (eds) Renewable Energy Sources: Engineering, Technology, Innovation. Springer Proceedings in Energy. Springer, Cham. Springer. 2018. pp. 571-581. doi.org/10.1007/978-3-319-72371-6_56

[9] Wójcik A., Krupa K., Łapczyńska-Kondon B., Francik S., Kwaśniewski D. The dynamic model of willow biomass production. In: Mudryk K., Werle S. (eds) Renewable Energy Sources: Engineering, Technology, Innovation. Springer Proceedings in Energy. Springer, Cham. Springer. 2018. pp. 631-638. doi.org/10.1007/978-3-319-72371-6_62

[10] Knapczyk A., Francik S., Wójcik A., Bednarz G. Influence of storing Miscanthus $\times$ Gigantheus on its physical-mechanical and energetic properties. In: Mudryk K., Werle S. (eds) Renewable Energy Sources: Engineering, Technology, Innovation. Springer Proceedings in Energy. Springer, Cham. Springer. 2018. pp. 651-660. doi.org/10.1007/978-3-319-72371-6_64 
[11]Fantozzi F., Buratti C. Life cycle assessment of biomass chains: Wood pellet from short rotation coppice using data measured on a real plant. Biomass and bioenergy, 34(12), 2010. pp. 1796-1804.

[12] Johansson L.S., Leckner B., Gustavsson L., Cooper D., Tullin C., Potter A. Emission characteristics of modern and old-type residential boilers fired with wood logs and wood pellets. Atmospheric environment, 38(25), 2014. pp. 4183-4195.

[13] Mudryk K., Frączek J., Ślipek Z., Francik S., Wróbel M. Chosen physico-mechanical properties of cutleaf coneflower (Rudbeckia laciniata L.). "Engineering for rural development". Jelgava. 2013. pp. 658-662.

[14] Mani. S., Tabil. L., Sokhansanj. S. (2006). Effects of compressive force. particle size and moisture content on mechanical properties of biomass pellets from grasses. Biomass and Bioenergy. 30. 2006. pp. 648-654.

[15] Bergström D., Israelsson S., Öhman, M., Dahlqvist S.A. Gref R., Boman C., Wästerlund I. Effects of raw material particle size distribution on the characteristics of Scots pine sawdust fuel pellets. Fuel Processing Technology, 89(12), 2008. pp. 1324-1329.

[16] Wróbel M., Frączek J., Francik S., Ślipek Z., Mudryk K. Influence of degree of fragmentation on chosen quality parameters of briquette made from biomass of cup plant Silphium perfoliatum L. "Engineering for rural development". Jelgava. 2013. pp. 653-657. Available at: http://www.tf.llu.lv/conference/proceedings2013/Papers/121_Wrobel_M.pdf

[17] Wrobel M., Fraczek J., Francik S., Slipek Z., Mudryk K. Modelling of unit contact surface of bean seeds using artificial neural networks. "Engineering for rural development". Jelgava. 2013. pp. 287-291. Available at: .

[18] Li Y., Liu H. High-pressure densification of wood residues to form an upgraded fuel, Biomass and Bioenergy 19. 2000. pp. 177-186.

[19] Lehtikangas P., Quality properties of pelletised sawdust, logging residues and bark, Biomass and Bioenergy 20. 2001. pp. 351-360.

[20] Okuda N., Sato M. Manufacture and mechanical properties of binderless boards from kenaf core, Journal of Wood Science 50. 2004. pp. 53-61.

[21] Krizan P., Vukelic D. Shape of pressing chamber for wood biomass compacting. International Journal for Quality Research, 2(3), 2008. pp. 205-209.

[22] Carone M.T., Pantaleo A., Pellerano A. Influence of process parameters and biomass characteristics on the durability of pellets from the pruning residues of Olea europaea L. Biomass and Bioenergy, 35(1). 2011. pp. 402-410.

[23] ISO 17827-1:2016 Solid biofuels - Determination of particle size distribution for uncompressed fuels - Part 1: Oscillating screen method using sieves with apertures of $3.15 \mathrm{~mm}$ and above

[24] ISO 17827-2:2016 Solid biofuels - Determination of particle size distribution for uncompressed fuels - Part 2: Vibrating screen method using sieves with aperture of $3.15 \mathrm{~mm}$ and below

[25] Niemczyk M., Kaliszewski A., Jewiarz M., Wróbel M., Mudryk K. Productivity and biomass characteristics of selected poplar (Populus spp.) cultivars under the climatic conditions of northern Poland Biomass and Bioenergy, 111. 2018 pp. 46-51. doi.org/10.1016/j.biombioe.2018.02.002.

[26] ISO 17828:2015 Solid biofuels - Determination of bulk density

[27] ISO 18134-1:2015 Solid biofuels - Determination of moisture content - Oven dry method - Part 1: Total moisture - Reference method 